\title{
Substrate Amendment Effects on Potted Plant Production and Dry Weight Partition of Lantana camara
}

\author{
Panayiotis A. Nektarios ${ }^{1}$, Serafim Kastritsis, Nikolaos Ntoulas, \\ and Panayiota Tsiotsiopoulou \\ Laboratory of Floriculture and Landscape Architecture, Department of \\ Crop Science, Agricultural University of Athens, 75, Iera Odos, Athens, \\ 11855 , Greece
}

Additional index words. peat, perlite, urea formaldehyde resin foam, Fytofoam, Hydrocell, Fytocell

\begin{abstract}
Ten substrates were evaluated for their capacity to promote the growth of potted Lantana camara. The substrates consisted of different volumetric proportions of sandy loam soil (S), peat (P), perlite (Per), and urea formaldehyde resin foam (UFRF referred to as $\mathrm{F}$ ), the latter in an effort to substitute peat use in horticulture. The substrates studied were: $S, S_{60}: P_{40}, S_{40}: P_{60}, S_{60}: F_{40}, S_{40}: F_{60}, P_{60}: F_{40}, \mathbf{P}_{40}: F_{60}, S_{40}: P_{30}: P_{30}$, $S_{40}: F_{30}: P_{30}$, and $P_{50}: P r_{50}$. Measurements included: 1$)$ substrate physical and chemical characteristics such as water characteristic curves, bulk density, total porosity, easily available water, and $\mathrm{pH} ; 2$ ) biometric measurements such as shoot length and number and number of flowers; and 3) determination of main and lateral stems, leaf, flower, and root dry weights. Results showed that substrates $P_{60}: F_{40}$ and $P_{40}: F_{60}$ retained excessive water in all tensions, whereas substrate $\mathbf{P}_{50}: P P_{50}$ exhibited increased water retention at saturation that was quickly reduced after $10 \mathrm{~cm}$ of tension. The non-amended soil (S) had the least water retention capacity and proved to be a slow-draining substrate. Supplementation either with peat or peat and perlite $\left(\mathbf{S}_{60}: \mathbf{P}_{40}, \mathbf{S}_{40}: \mathbf{P}_{60}\right.$, and $\left.\mathbf{S}_{40}: \mathbf{P}_{30}: \mathbf{P e r}_{30}\right)$ significantly increased water retention in the soil-based substrates. Soil-based substrates supplemented with UFRF retained less water compared with peat-amended soil-based substrates. Concerning plant growth, Lantana plants growing in the UFRF-amended substrates were unable to recover from frost injury and their evaluation was interrupted after winter as a result of total plant loss. The injury was attributed to the reduction of plant growth in UFRF-supplemented substrates before the occurrence of frost stress events. Soil-based substrates $\left(S_{,}, S_{60}: P_{40}\right.$, $S_{40}: P_{60}$, and $\left.S_{40}: P_{30}: P r_{30}\right)$ provided greater shoot growth, which was almost twofold compared with substrate $P_{50}: P_{50}$. Substrate $S_{40}: P_{30}: P_{30}$ produced the most lateral shoots and flowers over the whole study period, whereas $S_{40}: P_{60}$ produced the most flowers during the summer. Dry weights of both stem and lateral stems followed a similar pattern with the biometric measurements. However the non-amended soil (S) produced the highest leaf and root dry weights followed by substrates $S_{60}: P_{40}$ and $S_{40}: P_{60}$. It was concluded that both substrates $S_{40}: P_{60}$ and $S_{40}: P_{30}: P_{30}$ can successfully be used for Lantana nursery production as a result of their decreased bulk density, increased water retention capacity, adequate porosity, and promotion of shoot growth and flowering. Despite its high bulk density, substrate $S$ could be used in the production of Lantana plants for landscape use as a result of the increased root production.
\end{abstract}

Substrate selection is of major importance in ornamental potted plant production. The substrate should possess the correct physical and chemical characteristics and should drain freely while retaining the correct amount of moisture. Peat has been used extensively for indoor and outdoor pot production since the early 1950 s either on its own or combined with perlite. However, in recent years, worldwide reduction of peat depots, in conjunction with an effort to support the sustainability of peat forests by minimizing peat mining, has led to a search for alternative materials to be used as soil amendments.

Received for publication 18 Jan. 2011. Accepted for publication 8 Apr. 2011

${ }^{1}$ To whom reprint requests should be addressed; e-mail pan@aua.gr.
For several decades, this quest involved partial or total substitution of peat with composted agricultural and municipal byproducts, which served to reduce the agricultural use of peat while minimizing the organic load of agricultural and municipal waste toward landfills. Agricultural byproducts have included composted manure, cotton gin trash, and rice hulls (Papafotiou et al., 2001), olive mill wastes (Ntoulas et al., 2011; Papafotiou et al., 2004), and tree barks (Fain et al., 2008a, 2008b; Owen and Altland, 2008).

As an alternative to composted products, industrial byproducts can be recycled and used as soil amendments. Urea formaldehyde resin foam (UFRF) is produced by inflation of a resin with the addition of urea and formaldehyde. This foam has a porous structure and has the capacity to absorb water (up to $60 \%$ $\mathrm{v} / \mathrm{v}$ ) depending on the bulk density of the final product (Nektarios et al., 2003a, 2003b, 2005). It is environmentally friendly because it biodegrades over 15 to 20 years while slowly releasing nitrogen to plants that is estimated to be $5 \%$ per annum. Like many other substrates used for potted plants, it has an acidic $\mathrm{pH}$ (2.8 to 4.5) and may be used to lower the $\mathrm{pH}$ of alkaline soil. It is readily available in most countries.

UFRF could be considered a potential substitute for peat because it possesses similar physical characteristics and $\mathrm{pH}$ values. UFRF has been found to reduce bulk density and increase air-filled porosity in substrates for turfgrass growth (Nektarios et al., 2003a), in potted plants (Chan and Joyce, 2007; Nguyen et al., 2009), and in green roof substrates (Nektarios et al., 2003b). In addition, UFRF has been found to reduce soil bulk density in turfgrass that was subjected to moderate and severe soil compaction (Nikolopoulou and Nektarios, 2004). UFRF has also been reported to increase the water-holding capacity of soils and substrates, although the amount of easily available water to plants was not improved (Nektarios et al., 2003a, 2003b; Nguyen et al., 2009).

Despite its contribution to the improvement of substrate physical properties, UFRF has a moderate to negligible impact on plant growth. Nektarios et al. (2003a) did not observe any significant improvement on clipping yield, root growth, or tensile strength of turfgrasses grown in a non-amended and UFRF-amended sandy loam soil. However, turfgrass growth was improved by UFRF under moderate compaction but not under severe compaction (Nikolopoulou and Nektarios, 2004). In an intensive green roof substrate, UFRF amendment did not improve the growth of Lantana camara with respect to shoot number and length (Nektarios et al., 2003b) as well as shoot, leaf, and root dry weight (Tsiotsiopoulou et al., 2003). Chan and Joyce (2007) found increased plant height and stem diameter but minimal improvement on leaflet numbers of Flindersia schottiana saplings after incorporating UFRF in composted pine bark medium. Similarly, Nguyen et al. (2009) did not detect any differences in Orthosiphon aristatus shoot length or number by the incorporation of UFRF in either composted bark or sand media.

Therefore, the initial aims of the present study included the following: 1) to evaluate the potential of UFRF to substitute peat or perlite for pot plant production of Lantana; and 2) to determine the best substrate for production of potted Lantana. However, after winter dormancy and on failure of plants growing in UFRF-supplemented substrates to sprout, an additional aim was included, namely, to investigate the causes for UFRF to fail to support plant growth, because in previous studies, UFRF did not exhibit such detrimental effects (Nektarios et al., 2003b; Tsiotsiopoulou et al., 2003).

\section{Materials and Methods}

A field study was conducted at the Laboratory of Floriculture and Landscape Architecture of the Agricultural University of Athens 
(lat. $37^{\circ} 58^{\prime} 57^{\prime \prime} \mathrm{N}$, long. $23^{\circ} 42^{\prime} 17^{\prime \prime} \mathrm{E}$ ), Athens, Greece. The study was initiated on 6 Sept. 2001 and was completed 29 Oct. 2002. Ten substrates were evaluated for their capacity to support and improve the growth of L. camara potted plants. The substrate components included S, P, F, and Per and were formulated by mixing each component in volumetric proportions indicated by their subscripts: $100 \%(\mathrm{~S}),\left(\mathrm{S}_{60}: \mathrm{P}_{40}\right),\left(\mathrm{S}_{40}: \mathrm{P}_{60}\right),\left(\mathrm{S}_{60}: \mathrm{F}_{40}\right)$, $\left(\mathrm{S}_{40}: \mathrm{F}_{60}\right),\left(\mathrm{P}_{60}: \mathrm{F}_{40}\right),\left(\mathrm{P}_{40}: \mathrm{F}_{60}\right),\left(\mathrm{S}_{40}: \mathrm{P}_{30}: \mathrm{Per}_{30}\right)$, $\left(\mathrm{S}_{40}: \mathrm{F}_{30}: \operatorname{Per}_{30}\right)$, and $\left(\mathrm{P}_{50}:\right.$ Per $\left._{50}\right)$. The concept for selecting the specific substrates was based on comparisons between the effects on both the physical and chemical characteristics of selected substrates in which peat or perlite supplementation was substituted by UFRF and on the subsequent corresponding plant growth. Substrate selection was based on the results of previous studies that included UFRF as a soil amendment (substrates $\mathrm{S}, \mathrm{S}_{60}: \mathrm{F}_{40}, \mathrm{~S}_{50}: \mathrm{P}_{30}$ : $\mathrm{Per}_{20}, \mathrm{P}_{60}: \mathrm{F}_{40}$ were used by Nektarios et al., $2003 \mathrm{a}, 2003 \mathrm{~b}$ ) as well as the preference of Hellenic nursery producers for soil-based substrates in potted plant production. Nursery producers in the Mediterranean region claim that lightweight substrates used elsewhere require frequent irrigation at least twice a day and are prone to container instability. Therefore, they use soil-amended substrates instead especially wherever transport costs are small. Substrates $\mathrm{S}$ and $\mathrm{P}_{50}$ :Per $\mathrm{P}_{50}$ were used as controls, the former as an indicator of the physical and chemical alterations of soil-based substrates after using organic and inorganic amendments and the latter as a standard and commonly used nursery substrate (Papafotiou et al., 2001, 2004). More specifically in substrates $S_{60}: P_{40}$, $\mathrm{S}_{40}: \mathrm{P}_{60}$, and $\mathrm{S}_{40}: \mathrm{P}_{30}:$ Per $_{30}$, peat was substituted by $\mathrm{F}\left(\mathrm{S}_{60}: \mathrm{F}_{40}, \mathrm{~S}_{40}: \mathrm{F}_{60}\right.$, and $\left.\mathrm{S}_{40}: \mathrm{F}_{30}: \mathrm{Per}_{30}\right)$, whereas in substrates $\mathrm{P}_{60}: \mathrm{F}_{40}$ and $\mathrm{P}_{40}: \mathrm{F}_{60}$, the potential of $\mathrm{F}$ to substitute perlite was investigated.

The sandy loam soil that was used was composed of $78.9 \%$ sand, $8.0 \%$ silt, and $13.1 \%$ clay, having a cation exchange capacity of $6.23 \times 10^{-2} \mathrm{meq} \cdot 100 \mathrm{~g}^{-1}$, organic matter of $0.168 \% \mathrm{w} / \mathrm{w}$, electrical conductivity (EC) of $1.6 \mathrm{dS} \cdot \mathrm{m}^{-1}$, and $\mathrm{pH} 8.45$. The peat used was Lithuanian sphagnum peatmoss (Novalt, Lithuania) and had an organic matter content of $92 \% \mathrm{w} / \mathrm{w}$, total nitrogen $0.4 \% \mathrm{w} / \mathrm{w}$, and $\mathrm{pH}$ 3.7. Perlite (Isocon S.A., Athens, Greece) had a dry weight of 80 to $100 \mathrm{~kg} \cdot \mathrm{m}^{-3}$ with a particle size distribution that varied between 1 and $5 \mathrm{~mm}$ and $\mathrm{pH}$ 6.7. The UFRF (Fytofoam; Fytofoam Hellas Ltd., Athens, Greece) had a particle distribution of 0.05 to $50 \mathrm{~mm}$, a dry weight of $22 \mathrm{~kg} \cdot \mathrm{m}^{-3}, 60 \% \mathrm{v} / \mathrm{v}$ water-holding capacity, a slow biodegradation rate (of more than 20 years), and a $\mathrm{pH}$ of 2.5. The $\mathrm{F}$ was added as pre-wetted flakes after thoroughly rinsing to remove any remains of sulfuric acid. The $\mathrm{pH}$ of the substrates was corrected to $\approx 6.5$ with limestone $\left(2.8,10.5,10.5\right.$, and $4.0 \mathrm{~g} \cdot \mathrm{L}^{-1}$ for $\mathrm{S}_{40}: \mathrm{P}_{60}, \mathrm{P}_{60}: \mathrm{F}_{40}, \mathrm{P}_{40}: \mathrm{F}_{60}$, and $\mathrm{P}_{50}: \mathrm{Per}_{50}$, respectively) and sulfur $(1.4,1.2,0.7$, and $1.2 \mathrm{~g} \cdot \mathrm{L}^{-1}$ for $\mathrm{S}, \mathrm{S}_{60}: \mathrm{F}_{40}, \mathrm{~S}_{40}: \mathrm{F}_{60}$, and $\mathrm{S}_{40}: \mathrm{F}_{30}$ : $\operatorname{Per}_{30}$, respectively).

On 3 July 2001, cuttings taken from a single plant of $L$. camara were treated with indole-3-butyric acid and were placed in perlite substrate under mist. After $33 \mathrm{~d}$, the rooted cuttings were removed from the mist and were acclimatized for $12 \mathrm{~d}$. On 16 Aug. 2001, the rooted cuttings were transplanted to the appropriate substrate after perlite was thoroughly removed from their root system. On 6 Sept. 2001, the plants were pinched to a height of $20 \mathrm{~cm}$ to initiate the study with uniform plant height.

The substrates were placed in 10-L plastic pots with a depth of $27 \mathrm{~cm}$ and an internal diameter of $26 \mathrm{~cm}$. Ninety planted pots (10 substrates $\times$ nine plants per treatment) were placed on outdoor benches and manually irrigated all at the same time until drainage occurred at time intervals that were determined by the climatic conditions (approximately every 2 to $3 \mathrm{~d}$ ). Foliar fertilizer (Nutrileaf $60,20 \mathrm{~N}-8.7 \mathrm{P}-16.6 \mathrm{~K}$ plus micronutrients; Miller Chemical and Fertilizer Co., Hanover, PA) was applied at rate of $3.5 \mathrm{~g} \cdot \mathrm{L}^{-1}$ (9 and 28 Sept. 2001, 7 and 18 Oct. 2001, 9 Nov. 2001, 19 Mar. 2002, and 15 May 2002) in conjunction with granular fertilizer (Complesal 12$12-17$, having $6.5 \%$ as $\mathrm{NH}_{4}{ }^{+}-\mathrm{N}$ and $5.5 \%$ as $\mathrm{NO}_{3}-\mathrm{N} ; 12 \mathrm{~N}-5.2 \mathrm{P}-14.1 \mathrm{~K}-1.2 \mathrm{Mg}-8.0 \mathrm{~S} ;$ Agrevo Hellas S.A., Athens, Greece) that was applied at a rate of $10 \mathrm{~g} /$ pot on each of 4 Oct. 2001, 22 Nov. 2001, 29 Mar. 2002, 24 June 2002, and 18 Aug. 2002. All pots remained outdoors for the whole study period to simulate the most commonly applied practice in nurseries. Despite its tropical origin, Lantana used either as a pot plant or as a garden and ornamental plant under the climatic conditions of southern Greece usually drops its leaves in the winter and re-sprouts in the spring.

Substrate properties and moisture characteristic curves. To characterize physical properties of the substrates, a soil characteristic curve (three replications per substrate) was determined using a substrate column of $85 \mathrm{~cm}$ height that was composed by 17 rings, each $5 \mathrm{~cm}$ in height. The substrate column was placed in a watertight vessel at $20{ }^{\circ} \mathrm{C}$, and the water table was raised using a peristaltic pump at extremely low rates ( $8 \mathrm{~h}$ to be raised at $90 \mathrm{~cm}$ height). After $24 \mathrm{~h}$, the vessel was covered with a plastic liner at the top to prevent evaporation loss, and the water table was decreased slowly using the peristaltic pump until it reached the bottom of the first ring. The substrate column was left to drain for $24 \mathrm{~h}$, and then it was dismantled at $5-\mathrm{cm}$ intervals that were determined by the rings. Each ring (including the wet substrate) was weighed and then placed in pre-weighted aluminum trays and then in a dry oven at $105^{\circ} \mathrm{C}$ for $48 \mathrm{~h}$. Subsequently, the trays including the rings and the substrate were weighed again. From the substrate characteristic curve bulk density, total porosity and easily available water (EAW) were also determined.

The $\mathrm{pH}$ was determined in a 1:5 substrateto-water paste at both the initiation and at the end of the study. As a result of plant losses, the final $\mathrm{pH}$ in substrates $\mathrm{S}_{60}: \mathrm{F}_{40}$, $\mathrm{S}_{40}: \mathrm{F}_{60}, \mathrm{~S}_{40}: \mathrm{F}_{30}: \mathrm{Per}_{30}$, and $\mathrm{P}_{40}: \mathrm{F}_{60}$ was not determined.

Biometric and dry weight measurements. Plant growth rate measurements included the following: 1) shoot length; 2) shoot number; and 3) flower number. At the end of the study, plant dry weight partition was determined and included the following: 1) the main stem; 2) the lateral stems; 3) the leaves; 4) the buds and the flowers; 5) the senesced flowers; and 6) the roots. On 29 Oct. 2002, the plants were destructively sampled, and their parts were separated based on the previously mentioned measurements. The plant sections were ovendried for $48 \mathrm{~h}$ at $75^{\circ} \mathrm{C}$ and were then weighted. Based on the total dry weight of the aerial part of the plants and the root dry weight, the shoot to root $(S / R)$ ratio was calculated. Mean air temperature and precipitation (Fig. 1) were recorded by the Laboratory of General and Agricultural Meteorology of the Agricultural University of Athens.

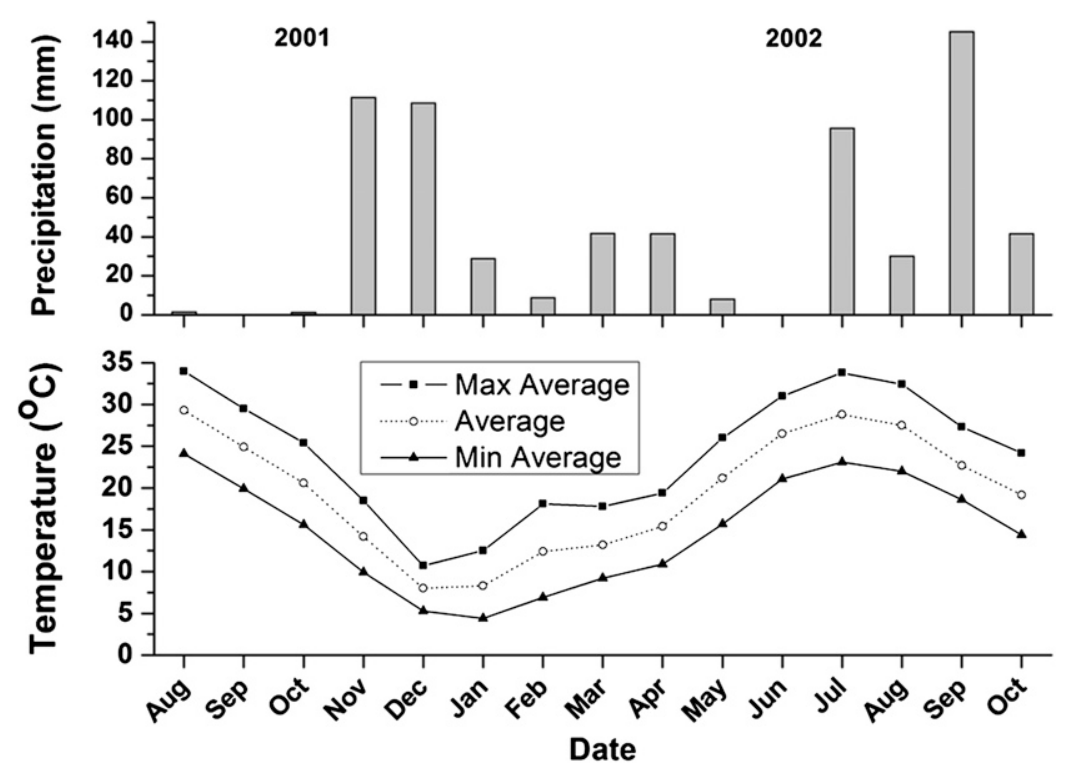

Fig. 1. Precipitation and maximum, minimum, and average air temperature for the study period (Sept. 2001 to Oct. 2002). 
Statistical analysis. A completely randomized design was used, and analysis of variance (ANOVA) was performed using JMP (SAS Inst., Cary, NC) statistical software. Because the main research interest of the present study was focused on the comparison of the substrate effects on plants growth in each separate sampling date, the statistical analysis concerning the total shoot length, number of lateral shoots, and flowering was performed as a distinct ANOVA on data collected on 16 Oct., 5 Dec. 2001, 5 Mar., 16 May, 15 June, 20 July, 28 Aug., and 16 Oct. 2002. Treatment means were compared using the Fisher protected least significant difference at a probability level $P<$ 0.05 .

\section{Results and Discussion}

Substrate properties and moisture characteristic curves. The corrected $\mathrm{pH}$ of the substrates was $\approx 6.5$ for all substrates at the initiation of the study. At the end of the study, $\mathrm{pH}$ increased approximately at 7.30 for substrates, $\mathrm{S}_{60}: \mathrm{P}_{40}, \mathrm{~S}_{40}: \mathrm{P}_{60}, \mathrm{P}_{60}: \mathrm{F}_{40}, \mathrm{P}_{40}: \mathrm{F}_{60}, \mathrm{~S}_{40}$ : $\mathrm{P}_{30}: \mathrm{Per}_{30}$, and $\mathrm{P}_{50}: \mathrm{Per}_{50}$ (Table 1). The $\mathrm{pH}$ of substrate $\mathrm{S}$ remained unaltered at 6.43 .

Soil had the highest bulk density (1.44 $\mathrm{g} \cdot \mathrm{cm}^{-3}$ ). The supplementation of soil with peat reduced the bulk density by $26.4 \%$ and $43.1 \%$ for substrates $\mathrm{S}_{60}: \mathrm{P}_{40}$ and $\mathrm{S}_{40}: \mathrm{P}_{60}$, respectively, whereas UFRF provided smaller bulk density reduction compared with peat supplementation $(18.1 \%$ and $30.6 \%$ reduction for substrates $\mathrm{S}_{60}: \mathrm{F}_{40}$ and $\mathrm{S}_{40}: \mathrm{F}_{60}$, respectively). The substrates with perlite participation reduced further bulk density; however, UFRF substrates still provided smaller bulk density reduction compared with peat $(46.5 \%$ and 39.6\% reduction for substrates $\mathrm{S}_{40}: \mathrm{P}_{30}$ : $\mathrm{Per}_{30}$ and $\mathrm{S}_{40}: \mathrm{F}_{30}: \mathrm{Per}_{30}$ compared with $\mathrm{S}$, respectively). The mixes that were composed by peat and UFRF as well as the peat-perlite mix provided minimal bulk densities (Table 1) and were the only ones that were within the suggested range for horticultural pot plant production (Yeager et al., 2007), whereas both $\mathrm{S}_{40}: \mathrm{P}_{30}: \mathrm{Per}_{30}$ and $\mathrm{S}_{40}: \mathrm{F}_{30}: \mathrm{Per}_{30}$ slightly exceeded the upper limit of $0.7 \mathrm{~g} \cdot \mathrm{cm}^{-3}$.

Total porosity was higher in substrates $\mathrm{P}_{60}: \mathrm{F}_{40}, \mathrm{P}_{40}: \mathrm{F}_{60}$, and $\mathrm{P}_{50}: \mathrm{Per}_{50}(70.1 \%, 72.4 \%$, and $65.4 \%$, respectively), whereas it was reduced in $\mathrm{S}$ and $\mathrm{S}_{60}: \mathrm{F}_{40}$ substrates $(38.2 \%$ and $39.5 \%$, respectively). In the remaining substrates, total porosity varied from $43 \%$ to $55.4 \%$ (Table 1). Based on the total porosity values suggested for horticultural pot production $(50 \%$ to $85 \%$ ), only the total porosity of substrates $\mathrm{S}_{40}$ : $\mathrm{P}_{60}, \mathrm{P}_{60}: \mathrm{F}_{40}, \mathrm{P}_{40}: \mathrm{F}_{60}, \mathrm{~S}_{40}: \mathrm{P}_{30}: \mathrm{Per}_{30}$, and $\mathrm{P}_{50}$ : Per $_{50}$ complied.

Easily available water was higher in substrates containing peat in increased amounts $\left(\mathrm{S}_{40}: \mathrm{P}_{60}\right.$ and $\left.\mathrm{P}_{50}: \mathrm{Per}_{50}\right)$ or peat with perlite $\left(\mathrm{S}_{40}: \mathrm{P}_{30}: \mathrm{Per}_{30}\right)$. In contrast, the least EAW was observed in $\mathrm{S}_{40}: \mathrm{F}_{30}: \mathrm{Per}_{30}$ and $\mathrm{S}(8.1 \%$ and $10.9 \%$, respectively). All other substrates amended with $\mathrm{F}$ and substrate $\mathrm{S}_{60}: \mathrm{P}_{40}$ provided moderate EAW that varied from $15.3 \%$ to $19.4 \%$. However, from all tested substrates, only $\mathrm{P}_{50}: \mathrm{Per}_{50}$ complied with the suggested EAW range of $23 \%$ to $35 \%$ vol., whereas $\mathrm{S}_{40}: \mathrm{P}_{60}$ had an EAW value of $22.6 \%$, which was close to the lower limit of $23 \%$ (Table 1 ).

Moisture characteristic curves (Figs. 2AB) revealed that the substrates performed significantly different with respect to their water-holding capacity. The non-amended soil $(\mathrm{S})$ retained the least moisture at saturation $(38.2 \% \mathrm{v} / \mathrm{v})$, but drainage was significantly retarded compared with all other substrates and occurred at a depth of $35 \mathrm{~cm}$ (as indicated by the tension that the water content decreased from the saturated water content of $38.2 \%$ ). The non-amended soil had the least moisture retention at saturation as a result of the smaller size and space of the pores that exist in sandy loam soil. These smaller pores also increased capillary forces and retarded drainage. The increased height of the perched water table in substrate $\mathrm{S}$, which reached $35 \mathrm{~cm}$ in height (Fig. 2A), is indicative of a different pore size distribution compared with the other substrates that subsequently lead to lower flow and drainage rates (Aggelides and Londra, 2000).

The water retention capacity of peatamended soil-based substrates $\left(\mathrm{S}_{60}: \mathrm{P}_{40}, \mathrm{~S}_{40}: \mathrm{P}_{60}\right.$, $\mathrm{S}_{40}: \mathrm{P}_{30}: \mathrm{Per}_{30}$ ) compared with that of $\mathrm{S}$ increased accordingly to the increase of peat participation in the substrates, because peat creates macropores within the substrate and absorbs water itself. An interesting observation is that substrates $\mathrm{S}_{40}: \mathrm{P}_{60}$ and $\mathrm{S}_{40}: \mathrm{P}_{30}: \mathrm{Per}_{30}$ had a very similar response in water-retaining capacity in all tensions indicating that $50 \%$ substitution of peat by perlite is not expected to alter the water retention characteristics of the soil-based substrate.

The increasing participation of UFRF amendment also increased the water retention capacity of the substrates accordingly. However, in the soil mixes, the substitution of peat by UFRF $\left(\mathrm{S}_{60}: \mathrm{F}_{40}\right.$, and $\left.\mathrm{S}_{40}: \mathrm{F}_{60}\right)$ provided smaller water retention at saturation as well as in the remaining tensions (Fig. 2B).
The only difference on the mentioned pattern was substrate $\mathrm{S}_{40}: \mathrm{F}_{30}: \mathrm{Per}_{30}$, which retained more water above the $40 \mathrm{~cm}$ of tension compared with substrate $\mathrm{S}_{40}: \mathrm{P}_{30}: \operatorname{Per}_{30}$ (Fig. 2A). The smaller water retention of UFRF-amended soil substrates compared with peat was the result of the lower water retention capacity of UFRF compared with peat (Londra P.A., personal communication) in conjunction with the morphology of the UFRF flakes that were surrounded by soil particles and not actually mixed with them, as in the case of peat. Therefore, UFRF flakes are not necessarily expected to increase the macroporosity of soil-based substrates.

The peat-based substrates that were supplemented with UFRF $\left(\mathrm{P}_{60}: \mathrm{F}_{40}\right.$, and $\left.\mathrm{P}_{40}: \mathrm{F}_{60}\right)$ retained high amounts of water in all tensions $(70.2 \%$, and $72.4 \% \mathrm{v} / \mathrm{v}$ at saturation, respectively) as a result of the inherited capacity of peat and UFRF to absorb large amounts of water. Their water characteristic curves indicated that water retention was increased even in low tensions and, therefore, it is anticipated that they would cause drainage problems in potted plant production. In the case that use of the peat-UFRF substrate is chosen, differentiated irrigation quantity and frequency would be required compared with other substrates. In addition, based on the water characteristic curves, UFRF cannot substitute perlite because the behavior of the peat-UFRF substrates was completely different compared with the peat-perlite $\left(\mathrm{P}_{50}: \mathrm{Per}_{50}\right)$ substrate.

Substrate $\mathrm{P}_{50}: \mathrm{Per}_{50}$, which is a common substrate with a broad application in potted plant production, had high water content at saturation $(65.4 \%)$, but it had a different behavior from the peat-UFRF substrates because its moisture content declined just after $10 \mathrm{~cm}$ of tension (Fig. 2A). This indicated that although water was retained in large amounts, there was sufficient drainage to provide adequate air porosity in $\mathrm{P}_{50}: \mathrm{Per}_{50}$ substrate to avoid water-logging and anaerobic conditions.

Biometric measurements. During the study, several substrates that contained UFRF failed to support plant growth and actually resulted in plant senescencing. More specifically, the plants in substrate $\mathrm{S}_{40}: \mathrm{F}_{60}$ started to die 2 months after transplanting (Oct. 2001), at which point four plants were lost, whereas substrates $\mathrm{S}_{40}: \mathrm{F}_{30}: \mathrm{Per}_{30}, \mathrm{~S}_{60}: \mathrm{F}_{40}, \mathrm{P}_{40}: \mathrm{F}_{60}$, and $\mathrm{P}_{40}: \mathrm{F}_{60}$ lost one plant during that period. However, from February to April, the mentioned substrates lost all their remaining

Table 1. Bulk density, total porosity, easily available water and $\mathrm{pH}$ values for the 10 substrates before and after the correction at the initiation of study and at its termination $\left(\mathrm{S}, \mathrm{S}_{60}: \mathrm{P}_{40}, \mathrm{~S}_{40}: \mathrm{P}_{60}, \mathrm{~S}_{60}: \mathrm{F}_{40}, \mathrm{~S}_{40}: \mathrm{F}_{60}, \mathrm{P}_{60}: \mathrm{F}_{40}, \mathrm{P}_{40}: \mathrm{F}_{60}, \mathrm{~S}_{40}: \mathrm{P}_{30}: \mathrm{Per}_{30}, \mathrm{~S}_{40}: \mathrm{F}_{30}: \mathrm{Per}_{30}\right.$, and $\left.\mathrm{P}_{50}: \mathrm{Per}_{50}\right)$.

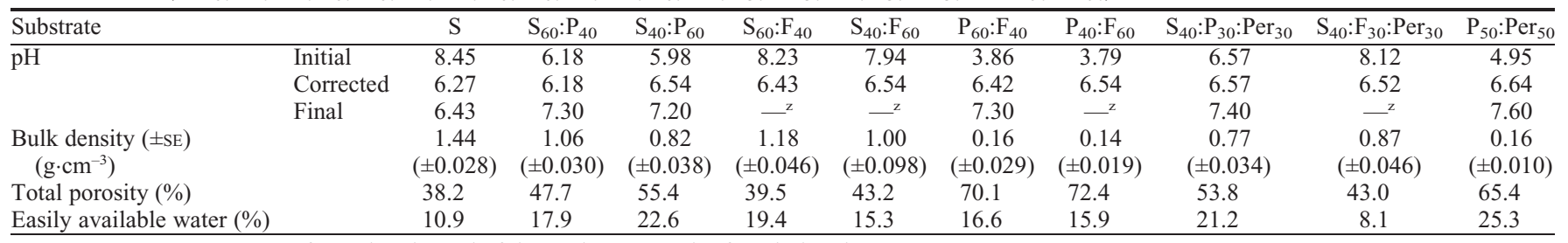

${ }_{\mathrm{p}} \mathrm{pH}$ measurement was not performed at the end of the study as a result of total plant loss.

$\mathrm{S}=$ sandy loam soil; $\mathrm{P}=$ peat; $\mathrm{Per}=$ perlite; $\mathrm{F}=$ urea formaldehyde resin foam (UFRF). 
plants except from substrate $\mathrm{P}_{60}: \mathrm{F}_{40}$ in which three plants survived to the end of the study.

The almost complete senescencing of the plants that were grown in UFRF raised significant concerns because the same substrate amendment has been already used in Lantana plants with no apparent problems (Nektarios et al., 2003b). It was speculated that the potential causes of this plant loss could be either phytotoxicity and/or climatic factors.

The first hypothesis was rejected because phytotoxic symptoms are immediately detectable, whereas in our study, plant growth in substrates $\mathrm{S}_{40}: \mathrm{F}_{30}: \operatorname{Per}_{30}$ and $\mathrm{S}_{60}: \mathrm{F}_{40}$ that contained UFRF provided adequate and sufficient growth until 5 Dec. 2001. Following the second hypothesis, and based on the phenological inspection, most of the plant losses occurred after January 2002 after frost, 4 months after their transplanting (except from the case of substrate $\mathrm{S}_{40}: \mathrm{F}_{60}$ that lost four plants in Oct. 2001). Lantana is a tropical plant that cannot tolerate reduced air and substrate temperatures. Cilliers and Neser (1991) and Sharma et al. (2005) described Lantana as a weed of the tropics that cannot tolerate temperatures below $5^{\circ} \mathrm{C}$. In January 2002, the temperature reached a minimum nightly temperature of $-2.8{ }^{\circ} \mathrm{C}$, which could injure the plants, especially those that did not exhibit increased growth during the fall and, therefore, did not store adequate carbohydrate reserves. Based on all of this, the observed plant losses were attributed to the reduced fall growth of the plants growing in substrates $\mathrm{S}_{40}: \mathrm{F}_{60}, \mathrm{~S}_{40}: \mathrm{F}_{60}, \mathrm{~S}_{40}: \mathrm{F}_{30}: \mathrm{Per}_{30}$, $\mathrm{P}_{60}: \mathrm{F}_{40}, \mathrm{P}_{40}: \mathrm{F}_{60}$, and $\mathrm{P}_{50}:$ Per $_{50}$.

Total shoot length. In fall of 2001, substrates $\mathrm{S}_{40}: \mathrm{P}_{60}, \mathrm{~S}_{40}: \mathrm{P}_{30}: \mathrm{Per}_{30}$, and $\mathrm{S}_{60}: \mathrm{P}_{40}$ provided increased shoot growth, as indicated by the total shoot length compared with the other treatments. Substrate $\mathrm{S}$ provided moderate growth, whereas substrates $\mathrm{S}_{40}: \mathrm{F}_{30}: \mathrm{Per}_{30}, \mathrm{~S}_{60}: \mathrm{F}_{40}$, $\mathrm{S}_{40}: \mathrm{F}_{60}, \mathrm{P}_{50}: \mathrm{Per}_{50}, \mathrm{P}_{60}: \mathrm{F}_{40}$, and $\mathrm{P}_{40}: \mathrm{F}_{60}$ did not promote shoot growth (Fig. 3). The reduced growth of soil-based substrates supplemented with UFRF indicated unfavorable substrate chemical or physical conditions. However, total porosity and EAW of the soil-based substrates supplemented with UFRF was not worse than those of other substrates such as $\mathrm{S}$ that managed to produce adequate shoot growth and re-sprout after the winter (Table 1). Therefore, it is suspected that an unfavorable chemical factor related to UFRF might have inhibited Lantana growth. It is speculated that UFRF might have released either urea or formaldehyde or some other compounds at a slow rate, which did not demonstrate any foliage symptoms. The reduced growth of the peat substrates that were supplemented by UFRF was also caused by the excessive water retention of the substrates, which probably resulted in anoxic conditions within the substrates.

During the winter, all substrates reduced their shoot growth as a result of the low temperatures that caused shoots to die back. Spring sprouting was directly related to the robust plant growth before the occurrence of low temperatures (total shoot length versus
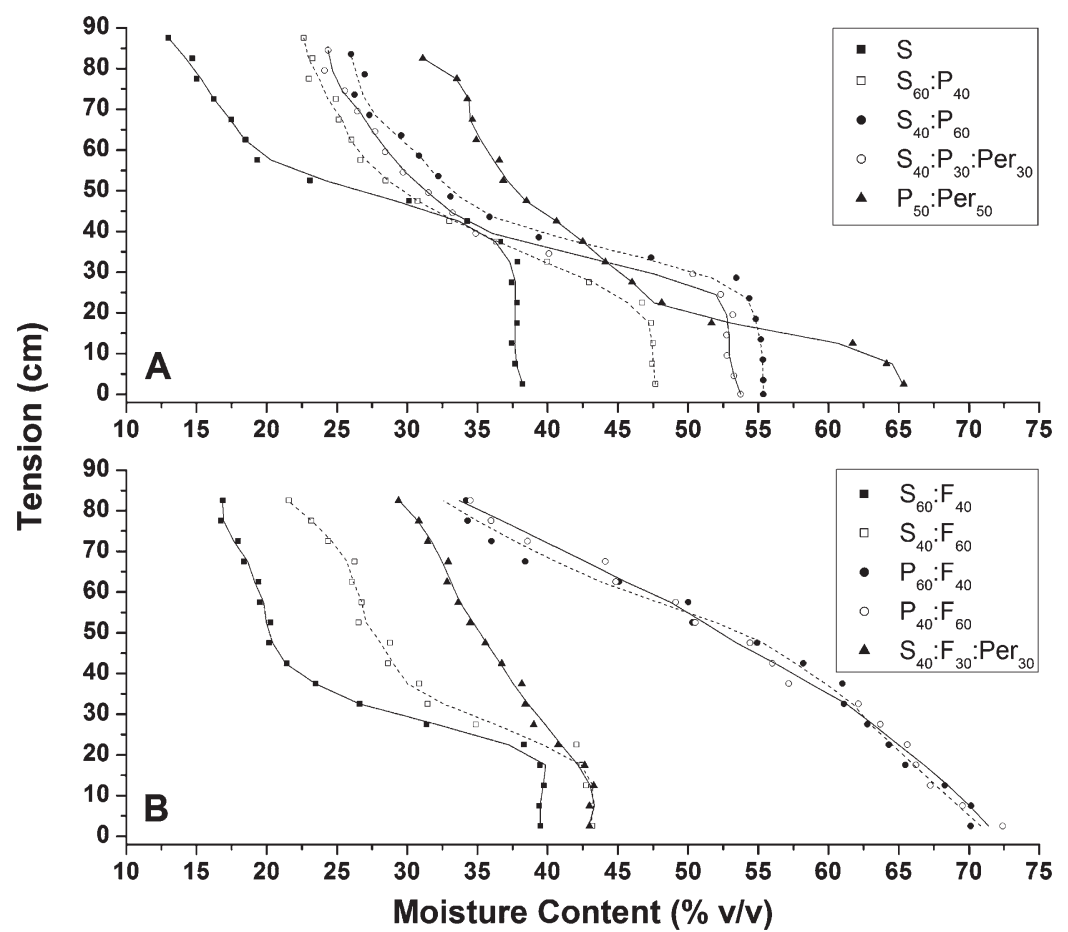

Fig. 2. Moisture characteristic curve for the substrates: (A) $\mathrm{S}, \mathrm{S}_{60}: \mathrm{P}_{40}, \mathrm{~S}_{40}: \mathrm{P}_{60}, \mathrm{~S}_{40}: \mathrm{P}_{30}: \mathrm{Per}_{30}$, and $\mathrm{P}_{50}: \mathrm{Per}_{50}$; and (B) $\mathrm{S}_{60}: \mathrm{F}_{40}, \mathrm{~S}_{40}: \mathrm{F}_{60}, \mathrm{P}_{60}: \mathrm{F}_{40}, \mathrm{P}_{40}: \mathrm{F}_{60}$, and $\mathrm{S}_{40}: \mathrm{F}_{30}: \mathrm{Per}_{30} . \mathrm{S}=$ sandy loam soil; $\mathrm{P}=$ peat; Per = perlite; $\mathrm{F}=$ urea formaldehyde resin foam - UFRF.

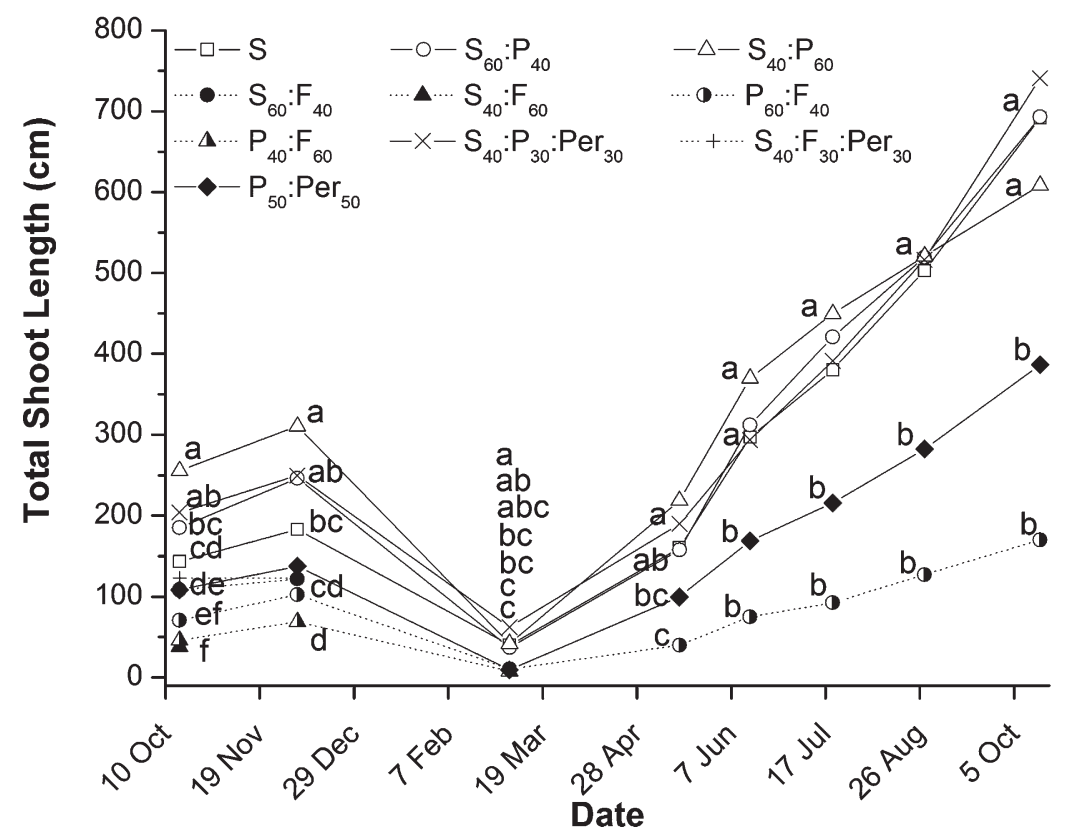

Fig. 3. Total shoot length (cm) of Lantana camara as affected by the substrate $\left(\mathrm{S}, \mathrm{S}_{60}: \mathrm{P}_{40}, \mathrm{~S}_{40}: \mathrm{P}_{60}, \mathrm{~S}_{60}: \mathrm{F}_{40}\right.$, $\mathrm{S}_{40}: \mathrm{F}_{60}, \mathrm{P}_{60}: \mathrm{F}_{40}, \mathrm{P}_{40}: \mathrm{F}_{60}, \mathrm{~S}_{40}: \mathrm{P}_{30}: \operatorname{Per}_{30}, \mathrm{~S}_{40}: \mathrm{F}_{30}:$ Per $_{30}$, and $\mathrm{P}_{50}:$Per$_{50} . \mathrm{S}=$ sandy loam soil; $\mathrm{P}=$ peat; Per $=$ perlite; $F=$ urea formaldehyde resin foam - UFRF. Means followed by the same letter in each measurement date are not significantly different at a probability level of $P<0.05$.

number of died plants had a correlation coefficient 0.73 ). In addition, substrates that did not promote top growth in fall lost most of their plants in the winter, and their further evaluation was obligatory interrupted. More specifically, after the cold period of winter, plants growing in substrates $\mathrm{S}_{60}: \mathrm{F}_{40}, \mathrm{~S}_{40}: \mathrm{F}_{60}$, $\mathrm{S}_{40}: \mathrm{F}_{30}: \operatorname{Per}_{30}$, and $\mathrm{P}_{40}: \mathrm{F}_{60}$ did not sprout, whereas substrates $\mathrm{P}_{50}: \mathrm{Per}_{50}$ and $\mathrm{P}_{60}: \mathrm{F}_{40}$ exhibited limited shoot growth. In contrast, all substrates contained soil without UFRF sprouted and provided increasing shoot growth.

From the six substrates that managed to sprout after the winter, shoot growth was promoted in substrates $\mathrm{S}_{40}: \mathrm{P}_{60}, \mathrm{~S}_{40}: \mathrm{P}_{30}: \operatorname{Per}_{30}$, 
$\mathrm{S}_{60}: \mathrm{P}_{40}$, and $\mathrm{S}$, whereas $\mathrm{P}_{50}: \mathrm{Per}_{50}$ provided moderate growth, and $\mathrm{P}_{60}: \mathrm{F}_{40}$ provided the least growth. In general, substrates that contained UFRF resulted in total shoot length that was significantly less compared with other substrates. In contrast, soil-based substrates exhibited increased shoot growth and survival rates from the frost, especially when they were amended with peat and/or perlite.

Number of lateral shoots. In fall of 2001, substrate $\mathrm{S}_{40}: \mathrm{P}_{60}$ provided the highest number of lateral shoots. Substrates $\mathrm{S}, \mathrm{S}_{40}: \mathrm{P}_{30}: \mathrm{Per}_{30}$, $\mathrm{P}_{60}: \mathrm{F}_{40}, \mathrm{P}_{40}: \mathrm{F}_{60}$, and $\mathrm{P}_{50}:$ Per $_{50}$ exhibited a moderate increase, whereas the substrates containing soil and UFRF $\left(\mathrm{S}_{40}: \mathrm{F}_{30}: \operatorname{Per}_{30}, \mathrm{~S}_{60}: \mathrm{F}_{40}\right.$, and $\left.\mathrm{S}_{40}: \mathrm{F}_{60}\right)$ had fewer lateral shoots compared with all the other treatments (Fig. 4).

After the winter frost, substrate $\mathrm{S}_{40}: \mathrm{P}_{60}$ produced the highest number of lateral shoots throughout the remaining study, except from the last sampling date. Soil-based substrates amended with peat or peat/perlite provided moderate or high numbers of lateral shoots. In contrast, substrates $\mathrm{P}_{50}: \mathrm{Per}_{50}$ and $\mathrm{P}_{60}: \mathrm{F}_{40}$ produced the least number of lateral shoots. The difference in the lateral shoot numbers between soil containing substrates and substrates $\mathrm{P}_{60}: \mathrm{F}_{40}$ and $\mathrm{P}_{50}: \mathrm{Per}_{50}$ was almost twofold.

The increased number of lateral shoots of substrate $\mathrm{S}_{40}: \mathrm{P}_{60}$ compared with the other soil-based substrates (before and after the winter period) can be attributed to more favorable substrate conditions as indicated by the values obtained for both the total porosity and EAW water retention (Table 1), which promoted shoot growth as well. In contrast, substrate $\mathrm{P}_{50}: \mathrm{Per}_{50}$ did not promote lateral shoot formation despite its good water retention probably as a result of its low nutrient retention capacity, which affected overall shoot growth.

Nektarios et al. (2003b) used almost identical green roof substrates and observed similar Lantana growth among substrates $\mathrm{S}$, $\mathrm{S}_{60}: \mathrm{F}_{40}$, and $\mathrm{S}_{50}: \mathrm{P}_{30}: \mathrm{Per}_{20}$. The same authors observed increased lateral shoot numbers for substrate $\mathrm{P}_{60}: \mathrm{F}_{40}$. The authors explained that prolific shoot production was probably a response either as a result of the increased EC or the increased water content of the substrate that caused water-logging conditions or a result of the combination of the two mentioned factors. However, the present study seems to indicate that the deteriorated physiological condition of the plants grown in $\mathrm{P}_{60}: \mathrm{F}_{40}$ substrate did not permit the production of increased number of lateral shoots. Nguyen et al. (2009) did not detect any differences in relative shoot number of $O$. aristatus grown either on sand or pine bark amended with UFRF and/or polyacrylamide gel (PAG).

Number of flowers. During the fall of 2001 , substrate $\mathrm{S}_{40}: \mathrm{P}_{30}: \mathrm{Per}_{30}$ provided earlier and increased flowering. The remaining soilbased substrates provided moderate flowering, whereas soilless substrates produced fewer flowers. Soil and soilless substrates that included UFRF provided reduced flowering except from substrate $\mathrm{S}_{60}: \mathrm{F}_{40}$, which provided moderate flowering in October (Fig. 5).

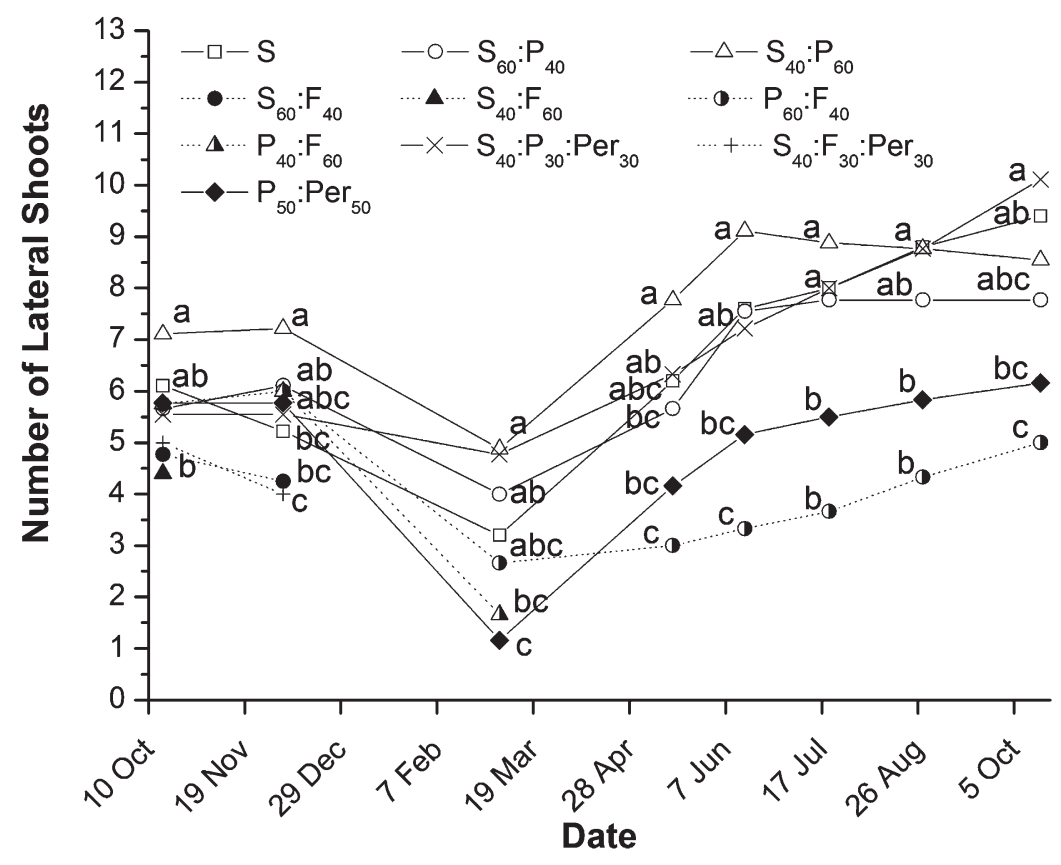

Fig. 4. Number of lateral shoots of Lantana camara as affected by the substrate $\left(\mathrm{S}, \mathrm{S}_{60}: \mathrm{P}_{40}, \mathrm{~S}_{40}: \mathrm{P}_{60}\right.$, $\mathrm{S}_{60}: \mathrm{F}_{40}, \mathrm{~S}_{40}: \mathrm{F}_{60}, \mathrm{P}_{60}: \mathrm{F}_{40}, \mathrm{P}_{40}: \mathrm{F}_{60}, \mathrm{~S}_{40}: \mathrm{P}_{30}: \mathrm{Per}_{30}, \mathrm{~S}_{40}: \mathrm{F}_{30}: \operatorname{Per}_{30}$, and $\mathrm{P}_{50}: \mathrm{Per}_{50} . \mathrm{S}=$ sandy loam soil; $\mathrm{P}=$ peat; Per = perlite; $F=$ urea formaldehyde resin foam - UFRF. Means followed by the same letter in each measurement date are not significantly different at a probability level of $P<0.05$.

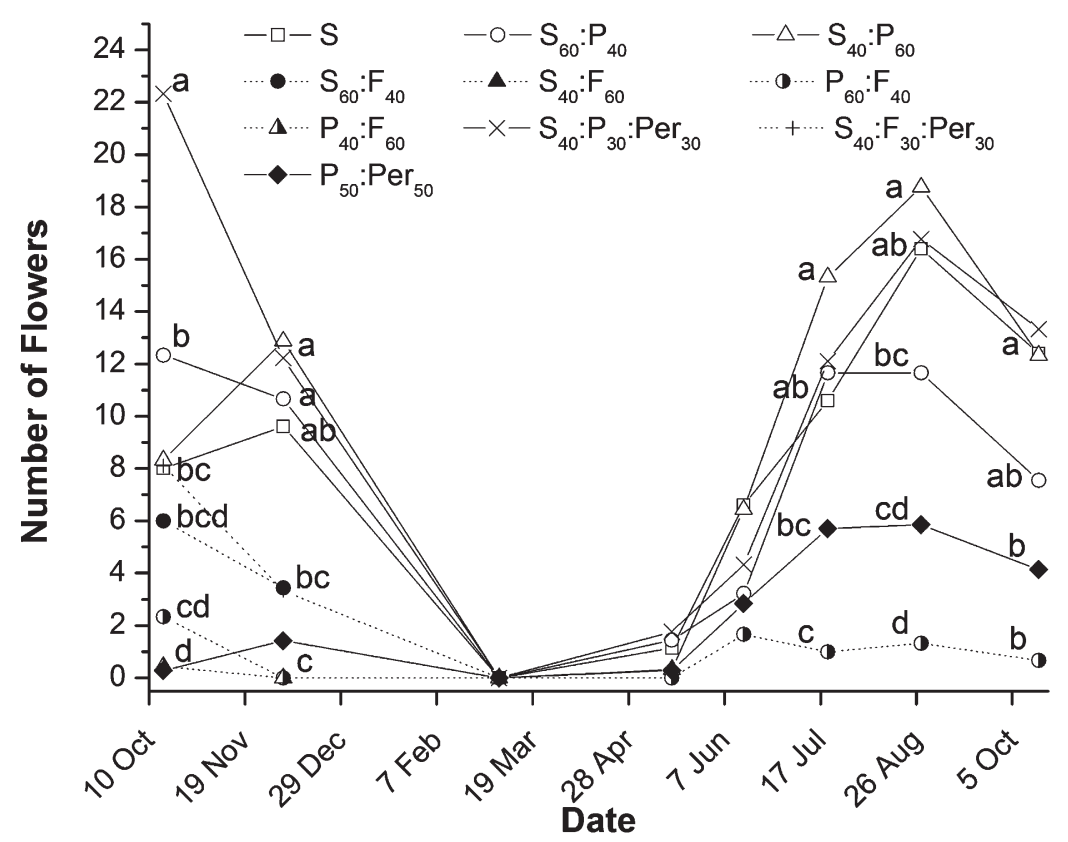

Fig. 5. Flower number of Lantana camara as affected by the substrate $\left(\mathrm{S}, \mathrm{S}_{60}: \mathrm{P}_{40}, \mathrm{~S}_{40}: \mathrm{P}_{60}, \mathrm{~S}_{60}: \mathrm{F}_{40}, \mathrm{~S}_{40}: \mathrm{F}_{60}\right.$, $\mathrm{P}_{60}: \mathrm{F}_{40}, \mathrm{P}_{40}: \mathrm{F}_{60}, \mathrm{~S}_{40}: \mathrm{P}_{30}: \mathrm{Per}_{30}, \mathrm{~S}_{40}: \mathrm{F}_{30}:$ Per $_{30}$, and $\mathrm{P}_{50}:$ Per $_{50} . \mathrm{S}=$ sandy loam soil; $\mathrm{P}=$ peat; Per $=$ perlite; $\mathrm{F}=$ urea formaldehyde resin foam - UFRF. Means followed by the same letter in each measurement date are not significantly different at a probability level of $P<0.05$.

Differences in flowering between the substrates, which recovered after the winter cold stress, were not apparent until July, when the soilbased substrates provided increased flower number compared with substrates $\mathrm{P}_{50}: \mathrm{Per}_{50}$ and $\mathrm{P}_{60}: \mathrm{F}_{40}$. Substrate $\mathrm{S}_{60}: \mathrm{P}_{40}$ provided a moderate flower number from July to Oct. 2002.

The increased flowering in the soil-based substrates amended with peat seems to follow and closely correlate with the general growth pattern of the plants. The explanation of this correlation can be that plants grown in soil mixtures showed increased growth and therefore accumulated more carbohydrates and resulted in longer lateral shoots with increased node numbers. Because Lantana inflorescences are produced in pairs in leaf axils (Sharma et al., 2005), substrates with longer and more 
Table 2. Dry weight of the main and lateral stems, leaves, roots, flowers and buds, senesced flower, total aboveground growth, and shoot/root ratio on 29 Oct. 2002 for each substrate $\left(\mathrm{S}, \mathrm{S}_{60}: \mathrm{P}_{40}, \mathrm{~S}_{40}: \mathrm{P}_{60}, \mathrm{P}_{60}: \mathrm{F}_{40}, \mathrm{~S}_{40}: \mathrm{P}_{30}: \mathrm{Per}_{30}\right.$, and $\left.\mathrm{P}_{50}: \mathrm{Per}_{50}\right)$.

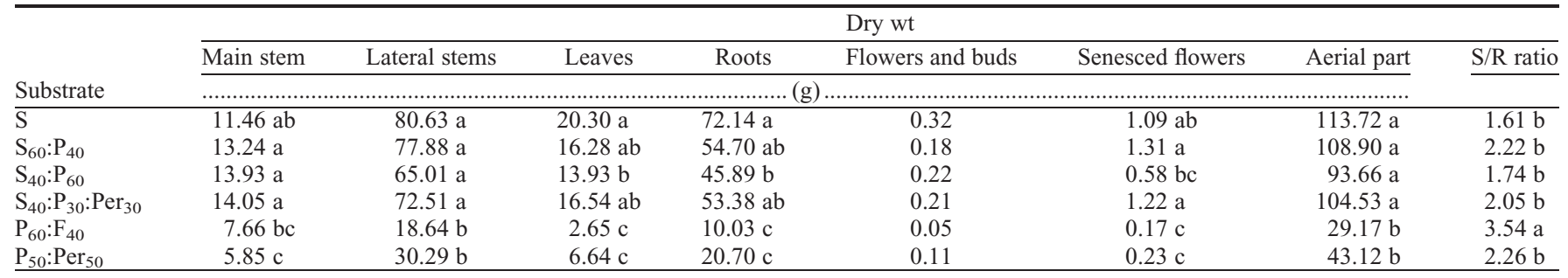

$\mathrm{S}=$ sandy loam soil; $\mathrm{P}=$ peat; $\mathrm{Per}=$ perlite; $\mathrm{F}=$ urea formaldehyde resin foam (UFRF). Means in each column followed by the same letter are not significantly different at a probability level of $P<0.05$.

shoots provided more plant sites capable for flowering.

The reduced plant growth before the winter prohibited the abundant flowering in the UFRF-amended substrates and $\mathrm{P}_{50}: \mathrm{Per}_{50}$. In contrast to our findings, Nguyen et al. (2009) found faster and increased flowering using UFRF and PAG as amendments for pine bark substrate of potted $O$. aristatus.

Dry weight partitioning. The highest dry weight of the main stem was provided by the soil-based substrates that were amended with peat and with peat/perlite. Non-amended soil (S) provided moderate dry weight, and the substrates $\mathrm{P}_{50}: \mathrm{Per}_{50}$ and $\mathrm{P}_{60}: \mathrm{F}_{40}$ provided the least dry weight (Table 2).

The dry weight of the stems of the plants grown in soil-based substrates increased compared with the plants grown in soilless mixtures (Table 2). In contrast, with the dry weight measurements of the main and the lateral stems, there was a clear advantage of substrate $\mathrm{S}$ concerning the dry weight of the leaves, which can be caused either from leaf enlargement or by an increase in the leaf number or the leaf thickness. Substrates $\mathrm{S}_{60}: \mathrm{P}_{40}$ and $\mathrm{S}_{40}: \mathrm{P}_{30}: \mathrm{Per}_{30}$ had moderate leaf dry weights, substrate $\mathrm{S}_{40}: \mathrm{P}_{60}$ had reduced leaf dry weight, whereas substrates $\mathrm{P}_{50}: \mathrm{Per}_{50}$ and $\mathrm{P}_{60}: \mathrm{F}_{40}$ had minimal leaf dry weights.

Root dry weight was increased in substrate $\mathrm{S}$, was moderate in substrates $\mathrm{S}_{60}: \mathrm{P}_{40}$ and $\mathrm{S}_{40}: \mathrm{P}_{30}: \mathrm{Per}_{30}$, and was reduced in substrate $\mathrm{S}_{40}: \mathrm{P}_{60}$. Substrates $\mathrm{P}_{50}: \mathrm{Per}_{50}$ and $\mathrm{P}_{60}: \mathrm{F}_{40}$ had minimal root dry weights. Substrate $S$ provided increased root growth compared with the other soil-based substrates amended with peat as a result of the increased leaf dry weight, which indicated an increased photosynthetically active surface of the plants. This led to increased carbohydrate production, which was then stored in the roots.

The reduced dry weight of $\mathrm{P}_{50}: \mathrm{Per}_{50}$ and $\mathrm{P}_{60}: \mathrm{F}_{40}$ was in accordance with the overall reduced plant growth in those substrates. However, substrate $\mathrm{P}_{50}: \mathrm{Per}_{50}$ resulted in an increased S/R (3.54), which was significantly higher compared with all other substrates. As a result of the increased water retention capacity of substrate $\mathrm{P}_{50}$ : Per $_{50}$, anoxia could be suspected as a factor for the reduced root growth. However, substrate $\mathrm{P}_{60}: \mathrm{F}_{40}$, which retained excessive amounts of water in all tensions, produced more root growth compared with $\mathrm{P}_{50}: \mathrm{Per}_{50}$ (Table 2). Therefore, the reduced shoot growth of $\mathrm{P}_{50}: \mathrm{Per}_{50}$ is suspected as the main cause for its reduced root growth, which is in accordance with the findings of Boyer et al. (2006).

\section{Conclusions}

The use of UFRF as a substrate amendment is inferior, and it cannot substitute the use of peat in the pot mixes for Lantana pot plant production. In addition, UFRF is expected to provide minimal or no benefits to plant growth, because it is substantiated by previous work in turfgrasses and potted plants by other researchers. Specifically, for Lantana potted plant production, the use of UFRF is expected to reduce growth and flowering.

From the present study, it has been established that potted plant production Lantana is best performed in $\mathrm{S}_{40}: \mathrm{P}_{60}$ and $\mathrm{S}_{40}: \mathrm{P}_{30}: \mathrm{Per}_{30}$ substrates as a result of their decreased bulk density, increased water retention, adequate porosity, and promotion of shoot growth and flowering. However, if the aim is the production of plants for landscape use and transportation costs are not of major concern, then despite its high bulk density, the sandy loam soil (S) could also be considered as a result of its increased root production.

\section{Literature Cited}

Aggelides, S.M. and P.A. Londra. 2000. Effects of compost produced from town wastes and sewage sludge on the physical properties of a loamy and a clay soil. Bioresour. Technol. 71:253259.

Boyer, C.R., G.B. Fain, C.H. Gilliam, H.A. Torbert, T.V. Gallagher, and J.L. Sibley. 2006. Evaluation of freshly chipped pine tree substrate for container-grown Lantana camara. HortScience 41:1027.

Chan, C.-L. and D.C. Joyce. 2007. Effects of urea formaldehyde foam soil amendment on growth and response to transient water deficit stress of potted Flindersia schottiana saplings. Sci. Hort. 114:112-120.

Cilliers, C.J. and S. Neser. 1991. Biological control of Lantana camara (Verbenaceae) in South Africa. Agr. Ecosyst. Environ. 37:57-75.

Fain, G.B., C.H. Gilliam, J.L. Sibley, and C.R. Boyer. 2008a. WholeTree substrates derived from three species of pine in production of annual vinca. HortTechnology 18:13-17.
Fain, G.B., C.H. Gilliam, J.L. Sibley, and C.R. Boyer. 2008b. WholeTree substrate and fertilizer rate in production of greenhouse-grown petunia (Petunia $\times$ hybrida Vilm.) and marigold (Tagetes patula L.). HortScience 43:700-705.

Nektarios, P.A., A.E. Nikolopoulou, and I. Chronopoulos. 2003a. Sod establishment and turfgrass growth as affected by urea-formaldehyde resin foam soil amendment. Sci. Hort. 100: 203-213.

Nektarios, P.A., P. Tsiotsiopoulou, and I. Chronopoulos. 2003b. Soil amendments reduce roof garden weight and influence the growth rate of Lantana. HortScience 38:618-622.

Nektarios, P.A., G. Tsoggarakis, A.E. Nikolopoulou, and D. Gourlias. 2005. Fertilization program and resin foam soil amendment effects on sod establishment. HortScience 40:475-479.

Nguyen, T.-T., D.C. Joyce, and S.-Q. Dinh. 2009. Effects of artificial amendments in potting media on Orthosiphon aristatus growth and development. Sci. Hort. 123:129-136.

Nikolopoulou, A.E. and P.A. Nektarios. 2004. Effects of resin foam soil amendment on the growth of turfgrass subjected to different compaction levels. Acta Hort. 661:177-181.

Ntoulas, N., P.A. Nektarios, and G. Gogoula. Evaluation of olive mill waste compost as a soil amendment for Cynodon dactylon turf establishment, growth and anchorage. HortScience 46:937-945.

Owen J., Jr. and J.E. Altland. 2008. Container height and Douglas fir bark texture affect substrate physical properties. HortScience 43:505508.

Papafotiou, M., J. Chronopoulos, G. Kargas, M. Voreakou, N. Leodaritis, O. Lagogiani, and S. Gazi. 2001. Cotton gin trash compost and rice hulls as growing medium components for ornamentals. J. Hort. Sci. Biotechnol. 76:431-435.

Papafotiou, M., M. Phsyhalou, G. Kargas, I. Chatzipavlidis, and J. Chronopoulos. 2004. Olive-mill wastes compost as growing medium component for the production of poinsettia. Sci. Hort. 102:167-175.

Sharma, G.P., A.S. Raghubanshi, and J.S. Singh. 2005. Lantana invasion: An overview. Weed Biol. Manage. 5:157-165.

Tsiotsiopoulou, P., P.A. Nektarios, and I. Chronopoulos. 2003. Substrate temperature fluctuation and dryweight partitioning of Lantana grown in four green roof growing media. J. Hort. Sci. Biotechnol. 78:904-910.

Yeager, T.H., D.C. Fare, J. Lea-Cox, J. Ruter, T.E. Bilderback, C.H. Gilliam, A.X. Niemiera, S.L. Warren, T.E. Whitwell, R.D. Wright, and K.M. Tilt. 2007. Best management practices: Guide for producing container-grown plants. 2nd Ed. Southern Nurserymen's Assoc., Marietta, GA. 